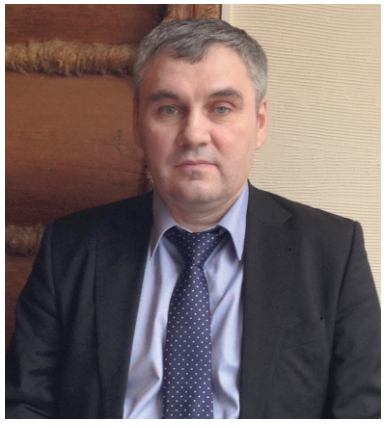

Сергей Александрович ДЕХАНОВ, профрессор кафредры гражданского права

и процесса

Московского

государственного гуманитарно-

экономического

университета, профрессор кафредры гражданского

права

Российской таможенной академии,

доктор юридических наук, дочент daad95@mail.ru

107150, Россия, г. Москва, ул. Лосиноостровская, д. 49

\section{СВОБОДА ОБЪЕДИНЕНИЙ (АССОЦИАЦИИ) КАК ДОМИНАНТА ОРГАНИЗАЦИОННО-ПРАВОВЫХ ФОРМ АДВОКАТСКИХ ОБРАЗОВАНИЙ}

\begin{abstract}
Аннотация. Статья посвящена изучению свободы объединений (ассоциаций) как разновидности политических свобод и влиянию конституционно-правового способа их закрепления на организационноправовые фрормы адвокатских образований. Автор последовательно анализирует фрранцузскую, немецкую и британскую модели свободы ассоциаций (объединений), приводит примеры влияния этих моделей на другие страны. В статье отмечается, что свобода объединений имеет конституционно-правовой способ закрепления и в Российской Федерации, который получает необходимую конкретизацию в гражданском законодательстве путем конструирования таких организационно-правовых фрорм, как ассоциация и союз. Автор приходит к выводу, что в российском праве объединение - это конституционно-правовой институт, а ассоциация и союз - гражданско-правовой. В соответствии с п. $18 \mathrm{~cm} .22$ и сm. 23 Федерального закона «Об адвокатской деятельности в Российской Федерации» к отношениям, возникающим в связи с учреждением, деятельностью и ликвидацией коллегии адвокатов и адвокатских бюро, применяются правила, предусмотренные для ассоциаций (союзов).

Значительное место в статье уделено рассмотрению сущности юридического лица и корпорации. Автор полагает, что юридическая конструкция (концепция) корпорации берет свое начало в деятельности легистов и канонистов. Настоящий перелом в изучении природы юридического лица произошел в связи с деятельностью Ф. Савиньи и его последователей: Б. Виндшайда и Г. Пухты. Изучением юридического лица занимались также Р. Иеринг, И. Блюнчли, И. Кунце, О. Гирке и выдающиеся российские ученые Г. Ф. Шершеневич, Н. М. Коркунов и др. Ключевые слова: свобода ассоциаций (объединений); французская, немецкая, британская модели свободы ассоциаций (объединений); конституция; корпорация; идеальная цель; хозяйственные общества; некоммерческое партнерство; коллегия адвокатов; адвокатское бюро.
\end{abstract}

DOI: $10.17803 / 2311-5998.2020 .75 .11 .054-061$ 
S. A. DEKHANOV,

Professor of the civil law and procedure, MGGEU, professor of the civil law, Russian customs Academy, Dr. Sci. (Law), Associate Professor

daad95@mail.ru

107150, Russia, Moscow, ul. Losinoostrovskaya,49

\title{
FREEDOM OF ASSOCIATION (ASSOCIATIONS) \\ AS THE DOMINANT ORGANIZATIONAL AND LEGAL FORMS OF LEGAL ENTITIES
}

\begin{abstract}
The article is devoted to the study of freedom of Association as a variety of political freedoms and the influence of the constitutional and legal method of securing freedom of Association (associations) on the organizational and legal forms of legal entities. The author consistently analyzes the French, German and British models of freedom of Association and gives examples of the influence of these models on other countries. Freedom of Association has a constitutional and legal form of consolidation in the Russian Federation, which receives the necessary specification in civil legislation by constructing such organizational and legal forms as Association and Union. The author comes to the conclusion that in Russian law, an Association is a constitutional legal institution, while an Association and a Union are civil law institutions. In accordance with paragraph 18 of article 22 of the Federal law "on advocacy in the Russian Federation" and article 23 of the law on relations arising in connection with the establishment, operation and liquidation of the bar Association and law offices. The article focuses on the essence of a legal entity and a Corporation. The author believes that the legal structure (concept) of the Corporation originates from the activities of legists and canonists. The corporatist concept of legists covered any legal entities that did not coincide with a natural (natural) person. According to the author, the real turning point in the study of the nature of a legal entity occurred in connection with the activities of F. Savigny and his followers: B. Windscheid and G. Pukhta. The legal entity was also studied by R. lering, I. Blunchli, O. Gierke and outstanding Russian scientists G. F. Shershenevich, N. M. Korkunov and others. Freedom of Association (associations), French, German, British model of freedom of Association (associations), Constitution, Corporation, ideal goal, business companies, non-profit partnership, bar Association, law office.

Keywords: freedom of association; french, german, british model of freedom of association; constitution; corporation; ideal goal; business companies; non-profit partnership; bar association; law office.
\end{abstract}

И мея различные основания, права и свободы могут быть выражены в индивидуальной и коллективной форме. Одной из свобод является свобода объединений или свобода ассоциаций.

Сегодня можно говорить о наличии трех различных правовых подходов к пониманию свободы ассоциаций — французский, немецкий и британский. Эти

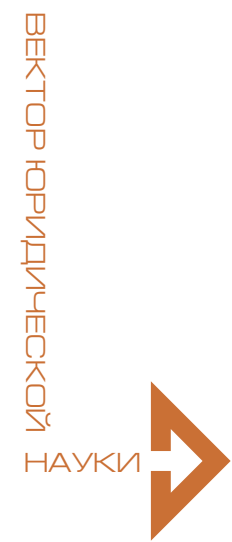


страны, пусть пока и в мягкой фооре, конкурируют между собой, но от исхода этой борьбы зависит будущее Европы, и не только.

Конечно, сами по себе модели государственного устройства не влияют напрямую на публичные свободы, включая и свободу ассоциаций, однако косвенное влияние на эти процессы является очевидным. Как, впрочем, очевидно и то, что значительное число стран придерживается фрранцузской модели конституционного оформления свободы ассоциаций.

Согласно фрранцузской модели, свобода ассоциаций признается только в отношении тех организаций (ассоциаций), которые созданы с иной целью, чем распределение прибыли, т.е. с идеальной целью.

Проиллюстрируем высказанный тезис на примере конституционного оформления этих политических свобод в отдельных европейских странах и в Канаде.

В силу ст. 12 Конституции Греции ${ }^{1}$ «греки имеют право создавать союзы и общества, не имеющие цели извлечения прибыли». Конституция Итальянской Республики² «признает и гарантирует неотъемлемые права человека — как отдельной личности, так и в социальных образованиях, в которых проявляется эта личность» (ст. 2). Конституцией Канады ${ }^{3}$ «гарантируется свобода ассоциаций» (ст. 2). Конституцией Андорры ${ }^{4}$ «признается право на объединение в законно дозволенных целях» (ст. 17). Согласно Конституции Бельгии ${ }^{5}$ «бельгийцы имеют право на объединение» (ст. 27). «Право создавать общественные объединения в любых законных целях без предварительного уведомления» предусмотрено Конституцией Дании $)^{6}$ (ст. 78.1). «Право граждан образовывать ассоциации и союзы» закреплено в законодательстве Ирландии (ст. 6.1.(iii) Конституции).

Как усматривается из приведенных конституционных положений, наиболее точно и последовательно цель социального образования, назначение которого - проявление и развитие личности, содержится в Конституции Итальянской Республики. В этом нет ничего удивительного: пусть римской юриспруденции и не удалось создать конструкцию юридического лица, а только сформулировать концепцию (учение) о совокупности лиц (universitas, corpus), основные признаки и черты юридического лица были выявлены именно римскими юристами.

Несмотря на то, что именно Французской Республике мы обязаны появлению первой указанной модели, Франция признала свободу ассоциаций лишь через 112 лет после провозглашения прав человека и гражданина (1789 г.), т.е. в 1901 г. В течение этих 112 лет принимались самые разные законы, имеющие целью не допустить легализацию свободы ассоциаций.

Так, Законом Ле Шапелье от 17 июня 1791 г. во Франции были запрещены всякие объединения, более того, ст. 291 УК Франции предусматривала, что создание

1 Конституция Греции // Конституции государств Европы. М. : Норма, 2001. Т. 1. С. 649.

2 Конституция Итальянской Республики // Конституции зарубежных государств : учебное пособие. М. : Бек, 1996. С. 243.

3 Конституционный акт Канады 1982 г. // Конституции зарубежных государств. С. 318.

4 Конституция Княжества Андорры // Конституции государств Европы. С. 231.

5 Конституция Бельгии // Конституции государств Европы. С. 345.

6 Конституция Дании // Конституции государств Европы. С. 649.

7 Конституция Ирландии // Конституции государств Европы. С. 811. 


\begin{tabular}{|c|c|}
\hline 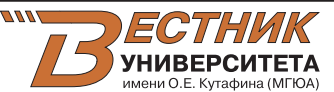 & $\begin{array}{l}\text { Деханов С. А. } \\
\text { Свобода объединений (ассоциаций) как доминанта } \\
\text { организационно-правовых форм адвокатских образований }\end{array}$ \\
\hline
\end{tabular}

той или иной ассоциации числом более 20 человек требует разрешения правительства, а за любую коалицию между рабочими вообще была предусмотрена уголовная ответственность ${ }^{8}$.

В то время как Франция запрещала свободы ассоциаций, другие страны двигались по пути ее признания. Прежде всего нужно назвать Великобританию, Италию, Испанию, Швейцарию. Так, Елизаветинский статут в Англии, закрепляющий право подданных на объединение, был принят еще в далеком 1601 г., Альбертинский статут (Statuto Albertino) в Италии - в 1848 г., Friendly societies Act (Акт об ассоциациях) в Ирландии - в 1896 г., Конституция Бельгия - в 1831 г., Конституция Люксембурга - в 1868 г., Конституция Испании - в 1869 г., Конституция Швейцарии - в 1874 г. $^{9}$

Нельзя не отметить, что многие века во Франции между режимом принудительного труда и режимом свободного труда удерживался корпоративный (цеховой) режим, который регулировал доступ к профрессии, определял условия труда. Только мастера могли определять условия труда, они вступали в соглашение с правительством или с властями в широком смысле в целях борьбы против забастовок и рабочих ассоциаций.

И в этом смысле средневековая корпорация по жестокости внутренних правил чем-то похожа на колхозы советского периода 1940-1950 гг., когда колхозники работали за трудодни и фактически были лишены всякой свободы. Конечно, в 60-80 гг. XX в. ситуация коренным образом изменилась.

От французской модели перейдем к ее фактическому антиподу - модели немецкой. Дело в том, что немецкая модель не ограничивается объединениями с идеальными целями, т.е. наделением конституционно-правовыми гарантиями только некоммерческих организаций, а охватывает и объединения, созданные с хозяйственными целями. К немецкой модели тяготеют Австрия, Швейцария, долгое время этой модели придерживалась и Япония, однако в современный период через формулу «человек и корпорация» считается, что Япония отошла от немецкой модели и формирует свою собственную.

Краткий экскурс в историю становления и развития права на ассоциацию в Германии позволяет сделать вывод о том, что это право было известно немецкому праву уже в Средние века. Интересный пример свободы ассоциаций в средневековой Германии приводит П. Г. Виноградов ${ }^{10}$. Суть примера сводится к следующемy. B XV в. Кельнский городской совет направляет запрос в адрес ученых-юристов с просьбой дать заключение по делу о так называемой ассоциации религиозных энтузиастов «Братство совместной жизни» (Brüder des gemeinsamen Lebens). Его предметом является вопрос о юридической квалификации этого братства, т.е. имеются ли достаточные правовые основания для того, чтобы распространить на подобную ассоциацию положения collegia licita римского права или нет ${ }^{11}$.

8 Барр Р. Политическая экономия : в 2 т. М. : Международные отношения, 1995. Т. 1. С. 315.

9 Барр Р. Указ. соч. С. 316.

10 Виноградов П. Г. «Римское право в средневековой Европе». М. : Издание Карцева, 1910. URL: https://naukaprava.ru/catalog/435/823/3433/22319?view=1 (дата обращения: 05.11.2020).

11 Виноградов П. Г. Указ. соч. 
Обосновывая свой запрос, заявители сообщают, что в некоторых регионах Германии люди объединяются в ассоциации для совместной жизни, разделяют между собой трудовые обязанности, заработки, движимое имущество. Одни члены братства занимаются перепиской разрешенных законом книг, другие, не умеющие писать, заняты ремеслами или другой работой. Члены братства вместе обедают, не просят милостыни, избирают ректора, которому они подчиняются, распределяют время для труда, отдыха. Основным мотивом пребывания этих людей в общине является их желание жить спокойно, их главная цель - это не выгода, но надежда, что, живя такими образом, они угождают Богу и служат ему.

В этой связи заявители спрашивают: можно ли признать такое «общежитие» законным, имеют ли право члены братства избирать ректора и принимать устав? Помимо этого, заявители просят юристов дать юридическое заключение о правовом статусе таких лиц. Третий вопрос: как следует расценивать поведение женщин, которые живут отдельно от супругов, шьют, прядут и ткут, добывая средства для описанного выше образа жизни? Юристы положительно ответили на первый вопрос. В отношении второго вопроса П. Г. Виноградов в своей работе данных не приводит. При ответе на третий вопрос юристы пришли к заключению, что «на основании авторитета Бартола женщины могут жить в таком общежитии только в том случае, если их труд в нем не противоречит женственности» ${ }^{12}$.

Самой древней, простой и оригинальной является англосаксонская модель. Страны английского права не употребляют термина «ассоциация» или «объединение», они остаются верны своему традиционному термину «корпорация». Однако не англичане создали корпоративную модель юридического лица. Первооткрывателями в этом вопросе были легисты и канонисты. Именно им принадлежит монопольное право авторства на конструкцию юридических субъектов, не совпадающих с физическими лицами (universitas, collegium, ecclesia), по отношению к которым канонисты стали применять термин persona, хотя и рассматривали их как существа бездушные и некрещеные.

Переломный момент в истории изучения юридического лица наступает в XIX в. в связи с научной деятельностью Ф. К. Савиньи и его последователей Виндшайда ${ }^{13}$, Г. Пухты и других ученых.

Для Савиньи юридическое лицо - это искусственный субъект права, фрикция, противопоставляемые человеку как естественному субъекту права. Как простая фрикция юридическое лицо не может иметь ни сознания, ни воли и, следовательно, недееспособно. Недостаток дееспособности восполняется представительством.

В системе юридических лиц Савиньи выделяет группу лиц, которые имеют естественное, или необходимое, существование (к таким лицам он относит общины), и лица, существование которых искусственное и произвольное (институты и вольные союзы).

Савиньи разделил все юридические лица на две группы: корпорации и институты, а также допустил возможность преобразования одного вида юридических

12 Виноградов П. Г. Указ. соч.

${ }^{13}$ См.: SavignyF. C. System des heutigen romischen Rechts. Bd. II. Berlin, 1840 ; Windscheid B. Lehrbuch des Pandekten rechts. Bd. I. 8. Aufl. Frankfurt, 1900. 


\begin{tabular}{|c|c|}
\hline 75 УНИВЕРСИТЕТА & $\begin{array}{l}\text { Деханов С. А. } \\
\text { Свобода объединений (ассоциаций) как доминанта } \\
\text { организационно-правовых форм адвокатских образований }\end{array}$ \\
\hline
\end{tabular}

лиц в другой. Современное немецкое корпоративное право активно пользуется изобретением Савиньи.

Учение Савиньи поддерживал профрессор Г. Ф. Шершеневич, а учение Р. Иеринга, сводившего функции юридического лица к обыкновенному техническому представителю (носителю, или дестинатору, прав) тех физических лиц, которые «стоят позади него», — профессор Н. М. Коркунов

Над теорией юридического лица трудились многие выдающиеся юристы, включая И. Блюнчли, И. Кунце.

Оригинальность и отличие Блюнчли от своих именитых коллег проявляется в том, что он рассматривал юридическое лицо (главным образом государство) как живое существо, обладающее подобно человеку телом и душой.

Самая яркая звезда на корпоративном небосклоне - Отто Фон Гирке. В своей работе «Deutsches Privatrecht» Гирке предложил собственную концепцию «О coюзных лицах (личностях)», разграничив государство, корпорации и институты.

«Для союзного лица Гирке вывел следующие положения:

1) союзное лицо правоспособно;

2) союзное лицо дееспособно;

3) союзное лицо есть лицо составное;

4) союзное лицо может быть, в свою очередь, членом высшего союзного лица и, во всяком случае, несуверенное союзное лицо есть часть государства» ${ }^{14}$.

Проводя аналогию между приведенными Гирке положениями и существующими в наши дни действующими корпорациями, можно сделать вывод, что благодаря Гирке были заложены основные характерные постулаты функционирования современных корпораций.

Свобода ассоциаций (объединений) является признанной общеевропейской ценностью и базовым положением для правового регулирования коммерческих и некоммерческих организаций в Европейском Союзе; эти вопросы также нашли свое глубокое отражение в Социальной хартии.

Конституционное право на объединение закреплено и в Конституции РФ. В соответствии со ст. 30 Конституции каждый имеет право на объединение. Свобода деятельности общественных объединений гарантируется. Никто не может быть принужден к вступлению в какое-либо объединение или пребыванию в нем. Конституционное право на объединение получает конкретизацию в гражданском законодательстве путем конструирования таких организационно-правовых форм, как ассоциация и союз.

В российском праве объединение - это конституционно-правовой институт, ассоциация и союз - гражданско-правовой.

В российском гражданском законодательстве ассоциацией или союзом признается объединение юридических лиц и (или) граждан, основанное на добровольном или в установленных законом случаях на обязательном членстве и созданное для представления и защиты общих, в том числе профессиональных, интересов, для достижения общественно полезных целей, а также иных не противоречащих закону и имеющих некоммерческий характер целей.

${ }^{14}$ См.: Деханов С. А. Актуальные проблемы защиты права предпринимателей в суде : учебное пособие. М., 2019. С. 22. 
Таким образом, скорее всего, мы тяготеем к французской модели. Правда, существенное отличие проявляется в том, что во Франции ассоциация это некая конституционная модель, тогда как у нас это конкретная организационно-правовая форма, которая имеет различные фрормы проявления, в том числе и неожиданные.

Так, например, в соответствии с п. 18 ст. 22 и ст. 23 Федерального закона «Об адвокатской деятельности в Российской Федерации» к отношениям, возникающим в связи с учреждением, деятельностью и ликвидацией коллегии адвокатов и адвокатских бюро, применяются правила, предусмотренные для ассоциаций (союзов). В ранее действовавшей норме к отношениям, возникающим в связи с учреждением, деятельностью и ликвидацией коллегии адвокатов и адвокатских бюро, применялись правила, предусмотренные для некоммерческих партнерств.

Если по своей природе коллегия адвокатов и может быть отнесена к ассоциации или союзу, то никак нельзя согласиться с законодателем, который поменял принадлежность адвокатского бюро и распространил и на него нормы об ассоциации, тогда как в прежней редакции, и это, на мой взгляд, было правильно, на отношения, возникающие в связи с учреждением, деятельностью и ликвидацией коллегии адвокатов и адвокатских бюро, распространялись правила, предусмотренные для некоммерческих партнерств.

Необходимо отметить, что основной организационно-правовой формой для адвокатских образований значительного числа европейских стран является как раз некоммерческое партнерство (объединение гражданского права): GB-Gesellschaft немецкого права, Advokaterselskab датского права, partnership британского и ирландского права. Но во Франции, как и в Бельгии, это association или cociete civile professionelle фрранцузского, бельгийского и люксембургского права, maatschap нидерландского права, sociedades civis португальского права, despachos collectivos испанского права. Очевидно, и мы решили пойти по французскому образцу ${ }^{15}$.

Таким образом, за более чем 400-летнюю историю правового закрепления свободы объединений (ассоциаций) как фрормы выражения публичных свобод они показали свою эффективность. Основные базовые положения содержатся в конституциях и международно-правовых документах, а конкретизация - в гражданских кодексах и специальном законодательстве.

\section{БИБЛИОГРАФИЯ}

1. Барр P. Политическая экономия : в 2 т. - М. : Международные отношения, 1995. - T. 1

2. Виноградов П. Г. Римское право в средневековой Европе. - М. : Издание Карцева, 1910.

3. Деханов С. А. Адвокатура в Западной Европе: опыт и современное состояние : автореф. дис. ... д-ра юрид. наук. - М., 2010.

${ }^{15}$ См.: Деханов С. А. Адвокатура в Западной Европе: опыт и современное состояние : автореф. дис. ... д-ра юрид. наук. М., 2010. 
4. Деханов С. А. Актуальные проблемы защиты права предпринимателей в суде : учебное пособие. - М., 2019.

5. Жаворонкова Н. Г., Шпаковский Ю. Г. Цифровизация в сфере экологической безопасности: административно-правовые аспекты // Юрист. - 2019. № 4. - C. 14-19.

6. Шпаковский Ю. Г., Романов Е. Ю. Социальная защита государственных служащих в современной России // Право и безопасность. - 2005. — № 3.

7. SavignyF. C. System des heutigen romischen Rechts. - Bd. II. - Berlin, 1840.

8. Windscheid B. Lehrbuch des Pandektenrechts. - Bd. I. - 8. Aufl. - Frankfurt, 1900. 